\title{
A Zeolite Imidazolate Framework ZIF-8 Catalyst for Friedel-Crafts Acylation
}

\author{
Lien T. L. NGUYEN, Ky K. A. LE, Nam T. S. PHAN* \\ Department of Chemical Engineering, Hochiminh City University of Technology, VNU-HCM, 268 Ly Thuong Kiet, District 10, \\ Ho Chi Minh City 740128, Viet Nam
}

\begin{abstract}
A zeolite imidazolate framework, ZIF-8, was synthesized and characterized by dynamic laser light scattering, X-ray powder diffraction, scanning electron microscopy, transmission electron microscopy, thermogravimetric analysis, Fourier transform infrared, atomic absorption spectrophotometry, and nitrogen adsorption measurements. The ZIF-8 was highly crystalline and porous with a surface area of over $1600 \mathrm{~m}^{2} / \mathrm{g}$. Friedel-Crafts acylation of anisole and benzoyl chloride proceeded well in the presence of ZIF-8 (2-6 mol\%) without the need for an inert atmosphere. The reaction afforded a selectivity of $93 \%-95 \%$ to the $p$-isomer. The solid catalyst can be separated from the reaction mixture by simple centrifugation and reused without significant degradation in catalytic activity. There was no leaching of active acid species into the reaction solution.
\end{abstract}

Key words: imidazolate framework; zeolite imidazolate framework ZIF-8; Friedel-Crafts acylation; porous material; catalysis CLC number: O643 Document code: A

Received 20 September 2011. Accepted 16 January 2012.

*Corresponding author.Tel: +84-8-917416018; Fax: +84-8-38637504; E-mail: ptsnam@hcmut.edu.vn

This work was supported by the Vietnam Department of Science and Technology through contract 40/2010/HD-NDT.

English edition available online at Elsevier ScienceDirect (http://www.sciencedirect.com/science/journal/18722067).

Metal-organic frameworks (MOFs) have emerged as a new class of porous crystalline materials with numerous potential applications in gas separation and storage, ion exchange, sensors, drug delivery, catalysis, luminescent and fluorescent materials, and optoelectronics materials [1-5]. By controlling the size and functionalization of the organic linkers, well-defined MOF structures with high surface areas and tunable pore sizes can be achieved, thus offering advantages over traditional microporous and mesoporous inorganic materials [6-8]. In the field of catalysis, several MOFs have already been used as solid catalysts for a variety of organic transformations [9-18]. Zeolite imidazolate frameworks (ZIFs), a new subclass of MOFs, have attracted significant attention as they combine the advantages from both zeolites and conventional MOFs [19,20]. During the past decade, research works have focused on synthesizing new ZIFs for their applications in gas capture and storage. As compared with conventional MOFs, there are few applications of ZIFs as catalysts or catalyst supports for organic transformations in the literature [15, 21-23].

Friedel-Crafts acylation of aromatic compounds with acid chlorides to form arylketones are fundamental and important processes in the production of pharmaceuticals, agrochemicals, and fragrances [24]. Traditionally, an excess over stoichiometric amounts of anhydrous strong Lewis acids such as $\mathrm{AlCl}_{3}, \mathrm{TiCl}_{3}, \mathrm{FeCl}_{3}$, or $\mathrm{SnCl}_{4}$ are required for these reactions [25]. These catalysts are highly moisture sensitive, and therefore moisture-free conditions have to be employed to maximize the atom economy of the reactions $[25,26]$. Moreover, these catalysts are highly toxic and corrosive, generate a large amount of waste, and cause difficult purification of the products [27]. For green chemistry, moisture-insensitive and easily handled solid acid catalysts should be developed [28]. A variety of solid catalysts have been employed for the Friedel-Crafts acylation reactions, including zeolites [29-31], hybrid zeolitic-mesostructured materials [32], mesoporous superacid catalyst [33], modified clay [34, 35], fly ash-supported cerium triflate [36], metal triflate loaded SBA-15 [37], Ga/SBA-15 supported on carbon nanofibers composite [38], mesoporous sulphated zirconia [39], mesoporous sieve AlKIT-5 [40], nanostructural zinc oxide hollow spheres [41], and silica gel supported aluminium trichloride [42]. In this work, we report the utilization of ZIF-8 as a heterogeneous catalyst for Friedel-Crafts acylation. High conversions were achieved with a catalytic amount of ZIF-8 $(2 \%-6 \%)$ without the need for an inert atmosphere.

\section{Experimental}

\subsection{Materials and instrumentation}


All reagents and starting materials were obtained commercially from Sigma-Aldrich and Merck, and were used as received without further purification unless otherwise noted. X-ray powder diffraction (XRD) patterns were recorded using a $\mathrm{Cu} K_{\alpha}$ radiation source in a D8 Advance Bruker powder diffractometer. Scanning electron microscopy (SEM) studies were conducted on a JSM 740 scanning electron microscope. Transmission electron microscopy (TEM) studies were performed using a JEOL JEM 1400 transmission electron microscope operated at $100 \mathrm{kV}$. The ZIF-8 samples were dispersed on holey carbon grids for TEM observation. Elemental analysis by atomic absorption spectrophotometry (AAS) was performed on a Shimadzu AA-6800. The particle size distribution of the ZIF-8 was determined by the dynamic laser light scattering (DLS) method using a LA 920. Fourier transform infrared (FT-IR) spectra were obtained on a Bruker TENSOR37 instrument with the sample dispersed on a potassium bromide pellet. Nitrogen adsorption measurements were conducted using a Quantachrome 2200e system. Samples were pretreated by heating under vacuum at $150{ }^{\circ} \mathrm{C}$ for $3 \mathrm{~h}$.

A Netzsch Thermoanalyzer STA 409 was used for thermogravimetric analysis (TGA) with a heating rate of 10 ${ }^{\circ} \mathrm{C} / \mathrm{min}$ under a nitrogen atmosphere. Gas chromatographic (GC) analyses were performed using a Shimadzu GC 17-A equipped with a flame ionization detector (FID) and a DB-5 column (length $=30 \mathrm{~m}$, inner diameter $=0.25 \mathrm{~mm}$, and film thickness $=0.25 \mu \mathrm{m})$. The temperature program for GC analysis was from 100 to $130{ }^{\circ} \mathrm{C}$ at $15^{\circ} \mathrm{C} / \mathrm{min}$, from 130 to $200{ }^{\circ} \mathrm{C}$ at $50{ }^{\circ} \mathrm{C} / \mathrm{min}$, from 200 to $215^{\circ} \mathrm{C}$ at $1.5^{\circ} \mathrm{C} / \mathrm{min}$, from 215 to $300{ }^{\circ} \mathrm{C}$ at $50{ }^{\circ} \mathrm{C} / \mathrm{min}$ and then held at $300{ }^{\circ} \mathrm{C}$ for 3 min. Inlet and detector temperatures were set at $300{ }^{\circ} \mathrm{C}$. $n$-Dodecane was used as an internal standard to calculate conversions. GC-MS analyses were performed using a Hewlett Packard GC-MS 5972 with a RTX-5MS column (length $=30 \mathrm{~m}$, inner diameter $=0.25 \mathrm{~mm}$, and film thickness $=0.5 \mu \mathrm{m})$. The temperature program for GC-MS analysis was from 60 to $280{ }^{\circ} \mathrm{C}$ at $10^{\circ} \mathrm{C} / \mathrm{min}$ and then held at $280{ }^{\circ} \mathrm{C}$ for $2 \mathrm{~min}$. The inlet temperature was set at $280{ }^{\circ} \mathrm{C}$. MS spectra were compared with the spectra in the NIST library.

\subsection{Synthesis of ZIF-8}

In a typical preparation [43], a solid mixture of zinc nitrate hexahydrate $\left(\mathrm{Zn}\left(\mathrm{NO}_{3}\right)_{2} \cdot 6 \mathrm{H}_{2} \mathrm{O}, 3.76 \mathrm{~g}, 14.7 \mathrm{mmol}\right)$ and 2-methylimidazole (H-MeIM, $0.43 \mathrm{~g}, 11.6 \mathrm{mmol}$ ) was dissolved in $240 \mathrm{ml}$ of $N, N^{\prime}$-dimethylformamide (DMF) that was then distributed into $20 \mathrm{ml}$ vials. The vial was tightly capped and heated at a rate of $5{ }^{\circ} \mathrm{C} / \mathrm{min}$ to $140{ }^{\circ} \mathrm{C}$ in a programmable oven and held at this temperature for $24 \mathrm{~h}$, then cooled at a rate of $0.4{ }^{\circ} \mathrm{C} / \mathrm{min}$ to room temperature. After removal of the mother liquor from the mixture, chloroform $(20 \mathrm{ml})$ was added to the vials. Colorless polyhedral crystals were collected from the upper chloroform layer and soaked in DMF $(3 \times 15 \mathrm{ml})$ for $3 \mathrm{~d}$. After that, the DMF was exchanged for dichloromethane $(\mathrm{DCM})(3 \times 15 \mathrm{ml})$ for $3 \mathrm{~d}$. The residual solvent was removed by vacuum at $200{ }^{\circ} \mathrm{C}$ for $6 \mathrm{~h}$, which yielded $0.30 \mathrm{~g}$ of white polyhedral crystals $(25 \%$ yield based on 2-methylimidazole).

\subsection{Catalytic test}

The Friedel-Crafts acylation of anisole with benzoyl chloride using the ZIF-8 catalyst was carried out in a magnetically stirred round bottom flask fitted with a reflux condenser. In a typical reaction, a mixture of anisole $(0.65 \mathrm{ml}, 6$ mmol), benzoyl chloride ( $1.4 \mathrm{ml}, 12 \mathrm{mmol})$, and $n$-dodecane $(0.2 \mathrm{ml})$ as an internal standard was added into a $50 \mathrm{ml}$ flask containing the ZIF-8 (69 mg, $6 \mathrm{~mol} \%$ ). The catalyst concentration was calculated with respect to the zinc/anisole molar ratio. The resulting mixture was stirred at $120{ }^{\circ} \mathrm{C}$ for $6 \mathrm{~h}$. The reaction conversion was monitored by withdrawing aliquots from the reaction mixture at fixed time intervals and quenching with an aqueous $\mathrm{NaOH}$ solution $(1 \%, 0.1$ $\mathrm{ml})$. The organic components were extracted using diethyl ether $(3 \times 1 \mathrm{ml})$, dried over anhydrous $\mathrm{Na}_{2} \mathrm{SO}_{4}$, and analyzed by GC. The reaction conversion was calculated based on anisole. The product identity was further confirmed by GC-MS. The ZIF-8 catalyst was separated from the reaction mixture by simple centrifugation, washed with copious amounts of anhydrous DCM, dried under vacuum at $100{ }^{\circ} \mathrm{C}$ for $5 \mathrm{~h}$, and reused. For the leaching test, a catalytic reaction at $120{ }^{\circ} \mathrm{C}$ was stopped after $1 \mathrm{~h}$, analyzed by GC, and centrifuged to remove the solid catalyst. The reaction solution was then stirred with heating to $120{ }^{\circ} \mathrm{C}$ for a further $5 \mathrm{~h}$, and monitored by GC as previously described to determine if there was any further reaction.

\section{Results and discussion}

\subsection{Catalyst synthesis and characterization}

The ZIF-8 was synthesized from the reaction between zinc nitrate hexahydrate and 2 methylimidazole in DMF at $140{ }^{\circ} \mathrm{C}$ according to a literature procedure [43]. In the zeolite imidazolate framework, zinc atoms in the ZIF-8 structure were connected to nitrogen atoms by 2-methylimidazolate (MeIM) linkers, which created nanosized pores formed by four, six, eight, and twelve membered ring $\mathrm{ZnN}_{4}$ tetrahedral clusters [20,44]. It was previously reported that the structure of ZIFs was similar to that of conventional zeolites in which the $\mathrm{T}-\mathrm{O}-\mathrm{T}$ bridges ( $\mathrm{T}$ $=\mathrm{Si}, \mathrm{Al}, \mathrm{P})$ in zeolites were replaced by $\mathrm{M}-\mathrm{IM}-\mathrm{M}$ bridges 
$(\mathrm{M}=\mathrm{Zn}, \mathrm{Co}, \mathrm{Cu})$. More interestingly, the bond angles in both frameworks are $145^{\circ}$ [20]. In the synthesis of porous MOF-based materials using DMF as solvent, a solvent exchange with DCM should be carried out after the solid crystals were formed to facilitate the evacuation of the material framework $[1,2,45]$. Subsequently, weakly interacting DCM molecules can be easily removed when the ZIF-8 sample is activated under vacuum [45]. The ZIF-8 was obtained as white polyhedral crystals with a yield of $25 \%$, which was comparable with that of previously reported procedures (normally around $20 \%-25 \%$ yields) [3].

The ZIF- 8 was then characterized by a variety of different techniques. A zinc loading of $4.17 \mathrm{mmol} / \mathrm{g}$ was found from the elemental analysis with AAS. The particle size distribution of the ZIF-8 observed by DLS analysis showed an average size of $159 \mu \mathrm{m}$. A very sharp peak below $10^{\circ}$ ( $2 \theta$ of 7.2) was observed in the XRD pattern of the ZIF-8, indicating that a highly crystalline material was achieved (Fig. 1). The overall XRD pattern of the ZIF-8 in this work were in good agreement with the patterns from single crystal data $[21,43,46,47]$. It was apparent that the ZIF-8 had better crystallinity as compared with silica-based materials such as SBA-15, SBA-16, and MCM-41 where broader peaks were observed on their diffractograms [48]. The SEM image showed well-shaped and high quality cubic crystals for the

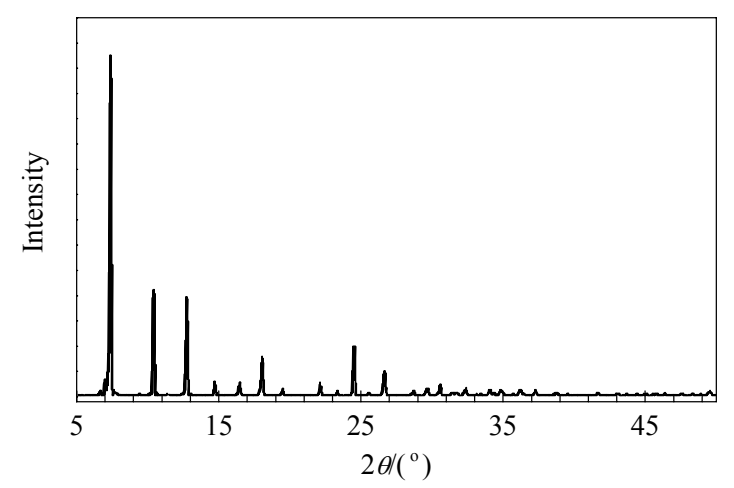

Fig. 1. XRD pattern of the ZIF-8.

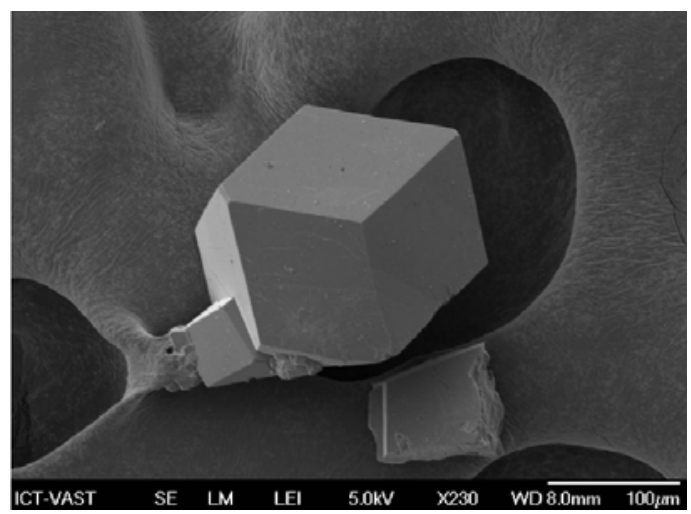

Fig. 2. SEM image of the ZIF-8.
ZIF-8 (Fig. 2). As expected, the TEM analysis revealed that the ZIF-8 possessed a porous structure (Fig. 3) which was different from that of conventionally used microporous and mesoporous inorganic materials. Nitrogen adsorption measurements (Fig. 4) indicated that the pore structure of the ZIF-8 was complex and contained both mesoporous and microporous pores.

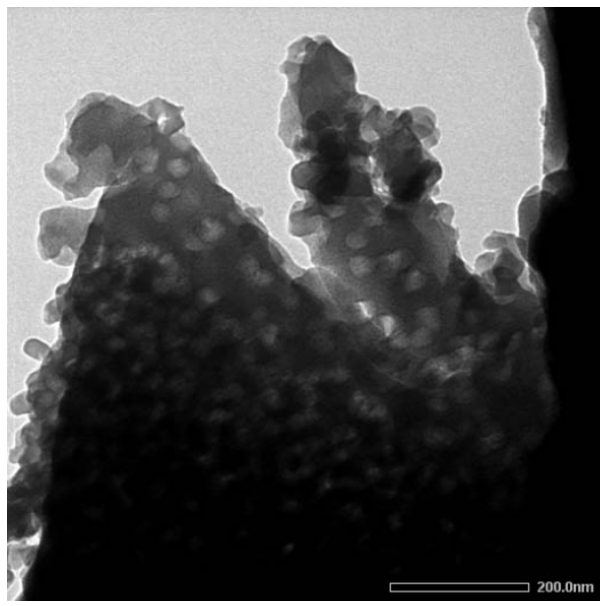

Fig. 3. TEM image of the ZIF-8.

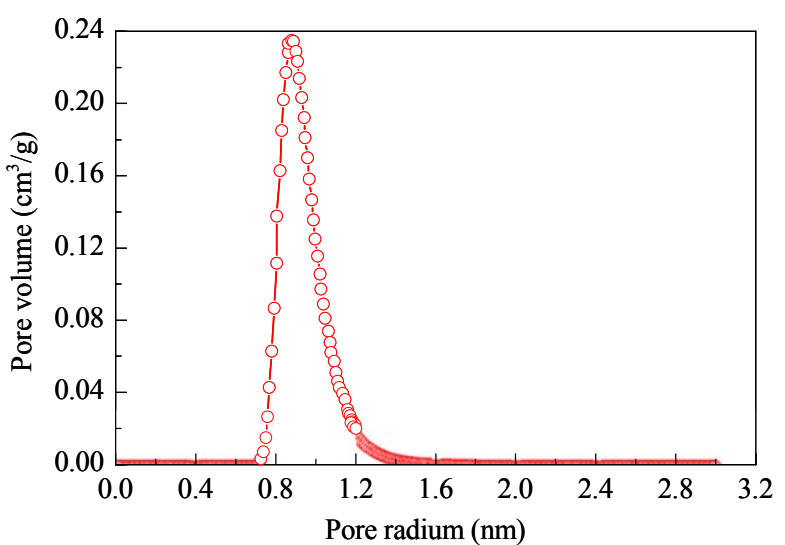

Fig. 4. Pore size distribution of the ZIF-8.

FT-IR spectra of the ZIF-8 showed a significant difference from that of the 2-methylimidazole linker (Fig. 5). In the FT-IR spectra of 2-methylimidazole, a strong and broad band from 3400 to $2200 \mathrm{~cm}^{-1}$ with the maximum at 2650 $\mathrm{cm}^{-1}$ was assigned to the $\mathrm{N}-\mathrm{H} \cdots \mathrm{N}$ hydrogen bond [49]. The resonance between the $\mathrm{N}-\mathrm{H} \cdots \mathrm{N}$ out-of-plane bending and the $\mathrm{N}-\mathrm{H}$ stretching vibrations was found at $1846 \mathrm{~cm}^{-1}$ [49]. These absorption bands were not seen in the spectra of the ZIF-8, confirming that the 2-methylimidazole linkers were fully deprotonated during the formation of the ZIF structure. In the TGA result for the ZIF-8, there was little weight loss in the temperature range of $200-400{ }^{\circ} \mathrm{C}$, indicating that the ZIF-8 was stable up to $400{ }^{\circ} \mathrm{C}$ (Fig. 6). The thermal stability of the ZIF-8 was therefore comparable with that reported in 


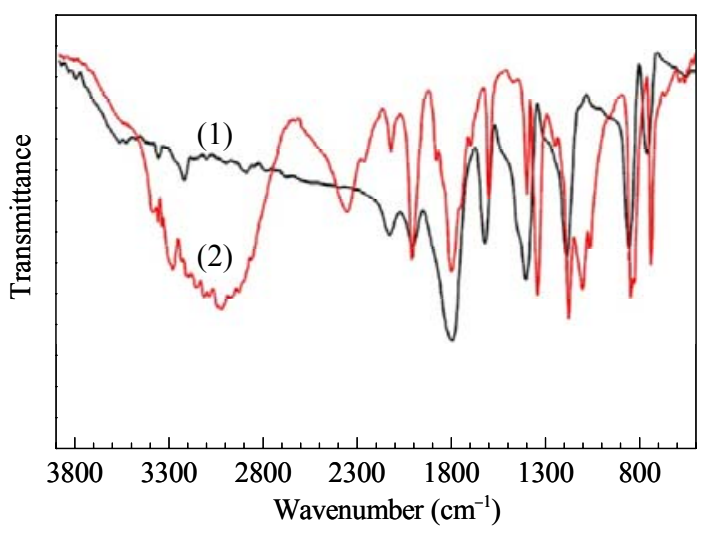

Fig. 5. FT-IR spectra of the ZIF-8 (1) and 2-methylimidazole (2).

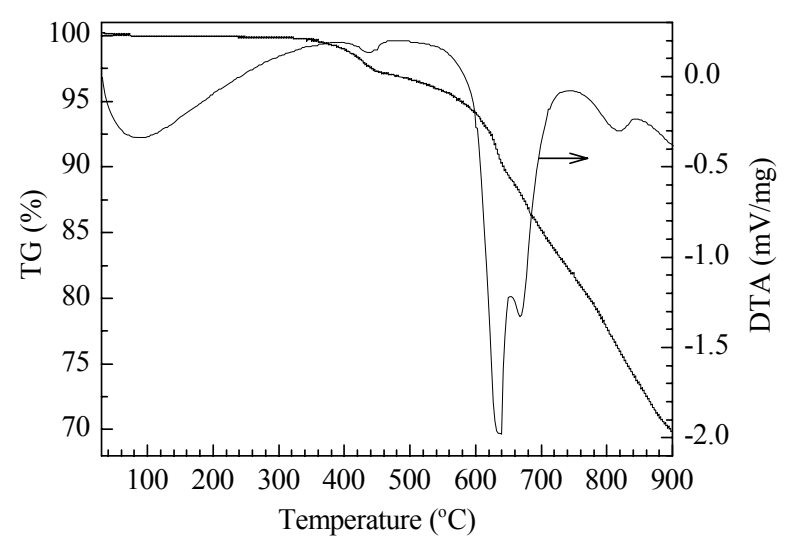

Fig. 6. TGA analysis of the ZIF-8.

the literature [43]. The specific surface area was up to 1632 $\mathrm{m}^{2} / \mathrm{g}$ for the ZIF-8, which was in good agreement with that in the literature. Several ZIF-8 samples with surface areas ranging from 1300 to $1810 \mathrm{~m}^{2} / \mathrm{g}$ were previously reported $[19,43,50-8]$.

\subsection{Catalytic test}

The ZIF-8 was assessed for its activity as a solid catalyst in the Friedel-Crafts acylation of anisole with benzoyl chloride to form $p$-benzoylanisole as the major product and $o$-benzoylanisole as the minor product (Scheme 1). In the ZIF-8 structure, the six-membered ring pore windows are as

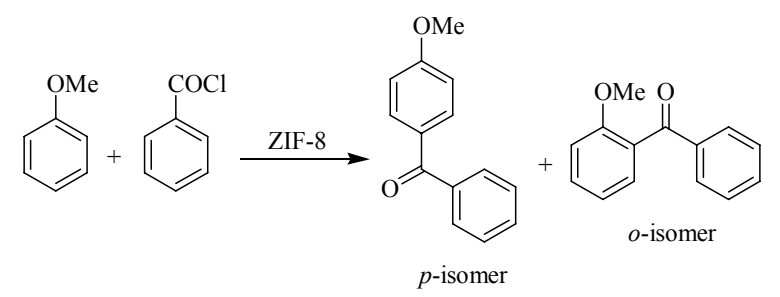

Scheme 1. Friedel-Crafts acylation of anisole with benzoyl chloride using ZIF-8 catalyst. narrow as $0.34 \mathrm{~nm}[20,51]$, and large molecules cannot enter the pores. Chizallet and coworkers [22] recently investigated the transesterification reaction using ZIF-8 as catalyst, and pointed out that all active sites are located on the external surface, and not in the micropores. It can be inferred that the Friedel-Crafts acylation of anisole with benzoyl chloride would also occur on the external surface of the ZIF-8 particles. Initial studies addressed the effect of temperature on the reaction conversion using $4 \mathrm{~mol} \%$ ZIF-8 catalyst and an anisole:benzoyl chloride molar ratio of 1:4 and 100, 110, and $120{ }^{\circ} \mathrm{C}$. Aliquots were withdrawn from the reaction mixture at different times and analyzed by GC to give kinetic data for the course of the reaction. A conversion of $58 \%$ was obtained after $6 \mathrm{~h}$ reaction at $120{ }^{\circ} \mathrm{C}$. Decreasing the temperature resulted in a significant drop in the reaction rate, with $44 \%$ and $36 \%$ conversions after $6 \mathrm{~h}$ at 110 and $100{ }^{\circ} \mathrm{C}$, respectively (Fig. 7(a)). The reaction selectivity remained almost unchanged at 93\%-95\% p-benzoylanisole (Fig. 7(b)).
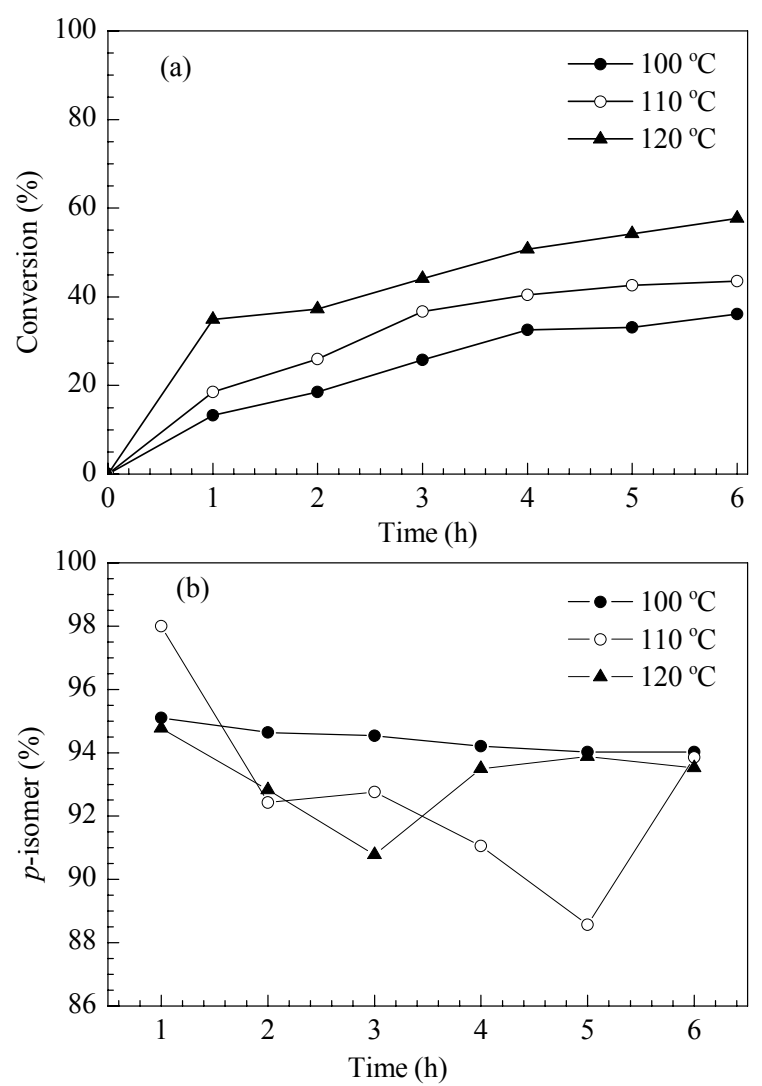

Fig. 7. Effect of temperature on reaction conversion (a) and selectivity (b).

For an organic transformation using a solid catalyst, the reagent ratio is an important factor. In this work, it was found that the reagent molar ratio had a profound effect on the reaction conversion. The data were from the reaction at 
$120{ }^{\circ} \mathrm{C}$ for $6 \mathrm{~h}$, using $4 \mathrm{~mol} \%$ ZIF- 8 catalyst with anisole:benzoyl chloride molar ratios of $1: 2,1: 3$, and $1: 4$. The reaction carried out with the reagent ratio of 1:4 afforded $58 \%$ conversion after $6 \mathrm{~h}$. Interestingly, decreasing the reagent ratio to $1: 4$ to $1: 3$ resulted in an enhancement in reaction rate, with $66 \%$ conversion after $6 \mathrm{~h}$. The value improved to $76 \%$ for the reaction using the anisole:benzoyl chloride molar ratio of 1:2 (Fig. 8(a)). From the experimental point of view, using a molar ratio of less than 1:2 would cause difficulty in stirring the reaction mixture containing the solid catalyst. In several cases, Friedel-Crafts acylation reactions are carried out under solvent-free condition with a large excess of one reagent as the reaction medium [25,27,52-54]. In this work, the Friedel-Crafts acylation reaction using the ZIF-8 catalyst was carried out under solvent-free condition with excess benzoyl chloride also acting as the solvent. In a heterogeneous reaction, mass transfer limitation in the system can have a significant effect on the reaction rate. Therefore, increasing the amount of solvent can lead to a drop in reaction rate. The reaction selectivity remained almost unchanged, with 93\%-95\% p-benzoylanisole being observed (Fig. 8(b)).

For a liquid phase organic transformation using a solid catalyst, there is the possibility that some active sites are dissolved into the liquid phase, and these leached species
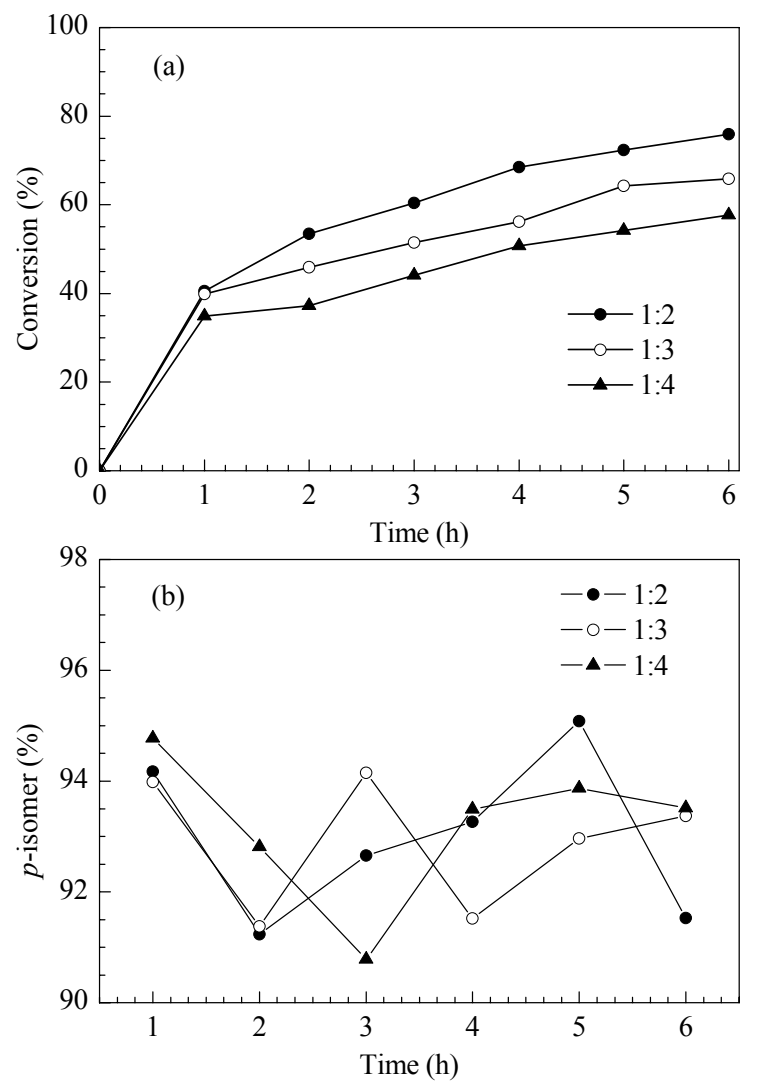

Fig. 8. Effect of anisole:benzoyl chloride molar ratio on reaction conversion (a) and selectivity (b). can contribute significantly to the reaction conversion [55]. In order to determine if leaching occurred in the Friedel-Crafts acylation reaction using the ZIF-8 catalyst, an experiment was carried out to estimate the contribution, if any, of leached active species. A simple centrifugation was performed during the course of the reaction to remove the solid ZIF-8. If the catalytic reaction continued, this would indicate that active species had been leached. The solid ZIF-8 catalyst was removed from the reaction mixture after $1 \mathrm{~h}$ reaction time by simple centrifugation (the reaction was started with $4 \mathrm{~mol} \%$ of fresh ZIF- 8 catalyst at $120{ }^{\circ} \mathrm{C}$ ). The liquid phase was then transferred to a new reactor vessel and stirred for an additional $5 \mathrm{~h}$ at $120{ }^{\circ} \mathrm{C}$ with aliquots being sampled at different times and analyzed by GC. Within experimental error, no further reaction was observed after the solid catalyst was removed from the reaction mixture. Therefore, it can be inferred that there was no leached active species in the liquid phase, and that the reaction could only proceed in the presence of the solid ZIF-8 catalyst (Fig. 9). It should also be noted that no conversion was observed for the reaction in the absence of the ZIF-8 catalyst.

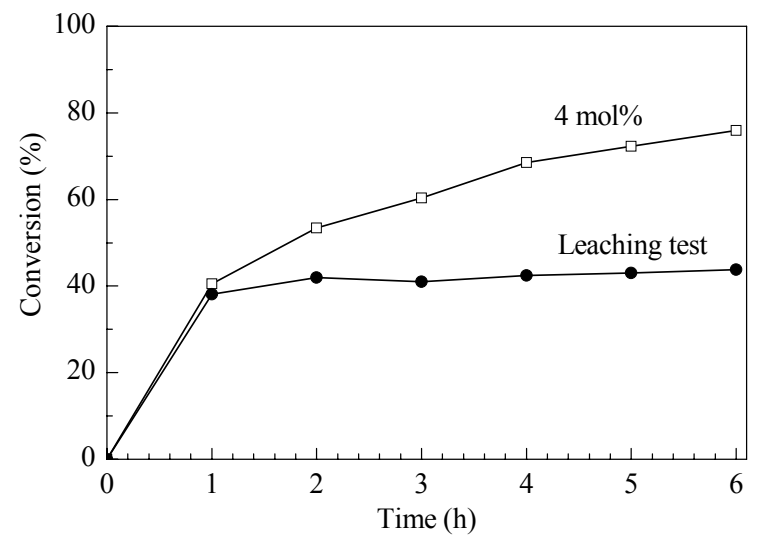

Fig. 9. Leaching test to indicate no active acid species leaching into the reaction solution.

We also investigated the effect of the catalyst concentration on the reaction conversion. It was previously reported that for the Friedel-Crafts acylation using traditional catalysts, an excess over stoichiometric amounts of the Lewis acid can be required, as a complex between the metal and the oxygen atom of the aroyl products can be formed in significant amounts $[27,56]$. The catalyst concentration can be reduced dramatically with several solid catalysts for this reaction, such as mesoporous superacid catalyst [33,36], metal triflate loaded SBA-15 [37], beta zeolite [29,30], and hybrid zeolitic-mesostructured materials [32]. Indeed, the Friedel-Crafts acylation reaction can require from less than $1 \mathrm{~mol} \%$ to more than $10 \mathrm{~mol} \%$ catalyst, depending on the nature of the catalyst as well as the substrate. In this work, it was found that the benzoylation reaction of anisole can 
proceed in the presence of a catalytic amount of the ZIF- 8 . The reaction has been carried out at $120{ }^{\circ} \mathrm{C}$ for $6 \mathrm{~h}$ with a reagent molar ratio of $1: 2$ in the presence of $2 \mathrm{~mol} \%, 4$ $\mathrm{mol} \%$, and $6 \mathrm{~mol} \%$ ZIF-8 catalyst. On increasing the catalyst concentration from $4 \mathrm{~mol} \%$ to $6 \mathrm{~mol} \%$, a conversion of $82 \%$ was achieved after $6 \mathrm{~h}$. As expected, the reaction proceeded more slowly for the case of $2 \mathrm{~mol} \%$ catalyst, although $67 \%$ conversion was still obtained after $6 \mathrm{~h}$ (Fig. 10(a)). The selectivity for the $p$-isomer was almost the same for all cases, with $93 \%-95 \%$ of $p$-benzoylanisole being obtained (Fig. 10(b)). Firouzabadi and co-workers previously used aluminum dodecatungstophosphate as a heterogeneous catalyst for the Friedel-Crafts acylation reaction between anisole and benzoyl chloride, and obtained a selectivity of $80 \%$ to the $p$-isomer [57]. In the same reaction using a zeolite-based catalyst, Choudhary and coworkers improved the $p$-isomer selectivity to $90 \%$ [58]. Singh and coworkers [59] also achieved a selectivity of $90 \%$ for the same reaction using $\mathrm{Cu}(\mathrm{OTf})_{2}$ as a catalyst. Kemnitz and coworkers [60] improved the selectivity to $93 \%-95 \%$ by using a borate zirconia solid acid catalyst. However, the reaction required the presence of nitrobenzene as solvent [60]. The selectivity of ZIF-8 in the Friedel-Crafts benzoylation of anisole was therefore comparable with those previously reported in the literature. Moreover, it was found that increasing the particle size of the ZIF-8 catalyst resulted in a significant drop in reaction rate. Conversions of $92 \%, 76 \%$,
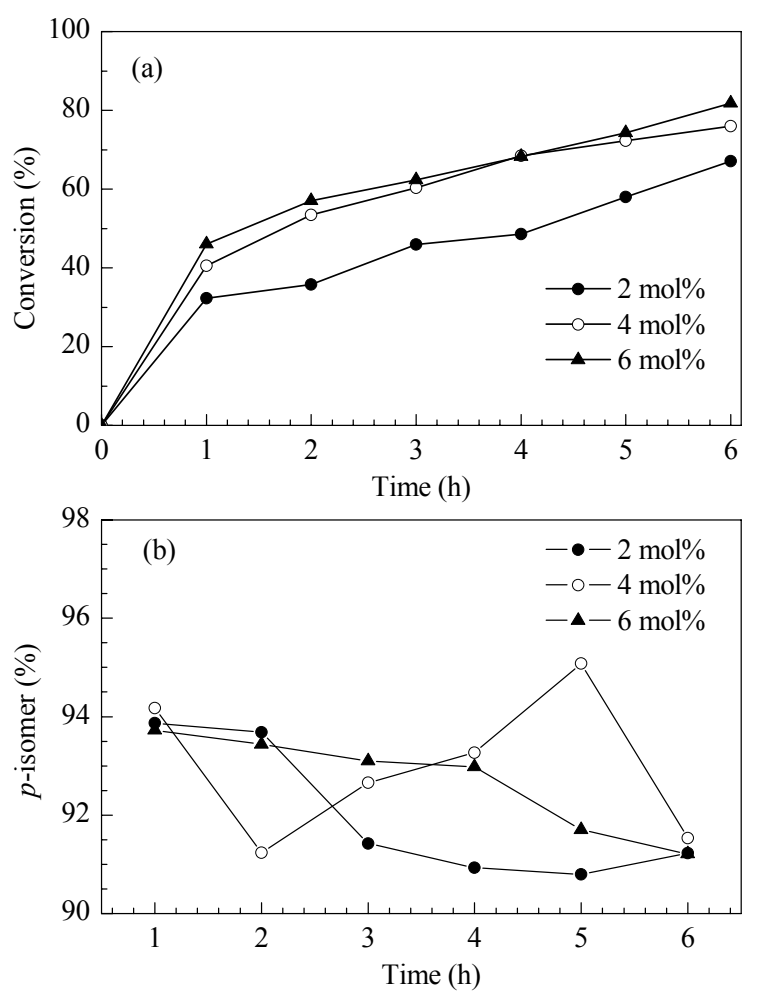

Fig. 10. Effect of catalyst concentration on reaction conversion (a) and selectivity (b).

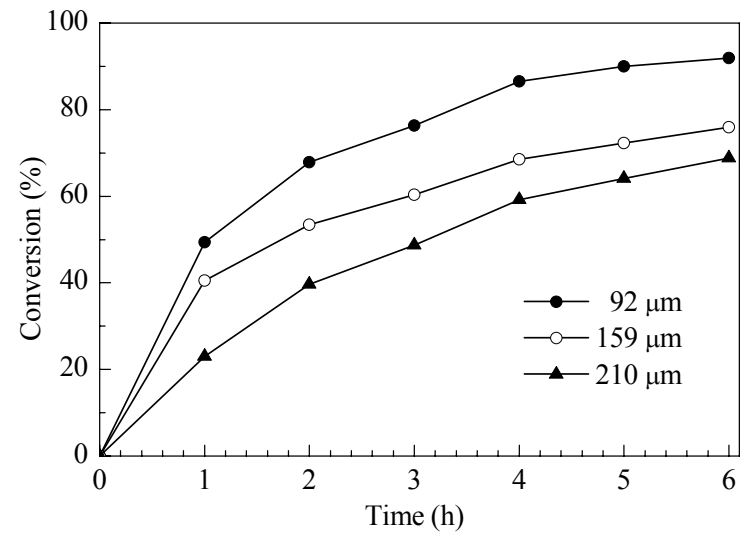

Fig. 11. Effect of catalyst particle size on reaction conversion.

and $69 \%$ were obtained after $6 \mathrm{~h}$ reaction using $4 \mathrm{~mol} \%$ ZIF-8 with particle sizes of 92,159 , and $210 \mu \mathrm{m}$, respectively (Fig. 11). Since the reaction occurred on the external surface of the ZIF-8 particles, smaller size crystals should exhibit higher catalytic activity due to the increased external surface of the smaller crystals [61].

The study was then extended to the Friedel-Crafts acylation of anisole with different acylating reagents, including benzoyl chloride, 4-methoxybenzoyl chloride, and 4-chlorobenzoyl chloride. The reaction was carried out for 6 $\mathrm{h}$ at $120{ }^{\circ} \mathrm{C}$ using $6 \mathrm{~mol} \% \mathrm{ZIF}-8$ catalyst with the reagent molar ratio of 1:2. Posternak and coworkers [56] previously reported a positive effect of electron-withdrawing groups present in the acyl chloride for Friedel-Crafts acylation. However, Fernandes and coworkers [27] found that the yield of Friedel-Crafts acylation was dramatically decreased in the presence of electron-withdrawing groups in the acyl chloride. In this work, it was observed that the presence of the methoxy group (electron-donating) in the benzoyl chloride structure accelerated the reaction. The acylation reaction of anisole with 4-methoxybenzoyl chloride afforded $87 \%$ conversion after $6 \mathrm{~h}$, while $82 \%$ conversion was obtained for the case of benzoyl chloride under identical conditions. The experimental result showed that the Friedel-Crafts acylation of anisole with 4-chlorobenzoyl chloride proceeded with more difficulty than in the case of benzoyl chloride, although $73 \%$ conversion was still observed after $6 \mathrm{~h}$ (Fig. 12(a)). Although the reaction using 4-methoxybenzoyl chloride gave a higher conversion than benzoyl chloride or 4-chlorobenzoyl chloride, a lower selectivity for the $p$-isomer was obtained with this acylating reagent (Fig. 12(b)). Chizallet and coworkers [22] previously investigated the presence of acid-basic sites in the ZIF- 8 by combining $\mathrm{CO}$ adsorption monitored by FT-IR and DFT calculations, and confirmed that some strong Lewis acid sites (in particular ZnII species) and strong Brönsted acid sites ( $\mathrm{NH}$ groups), together with basic sites, existed on the 

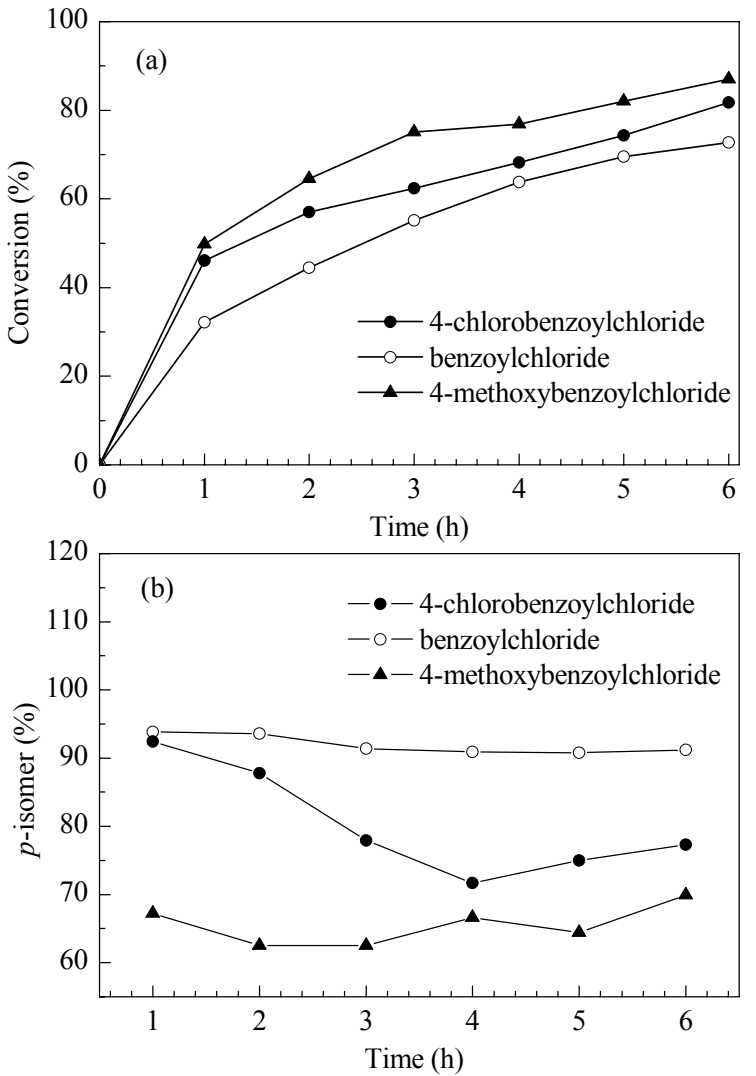

Fig. 12. Effect of different acylation reagents on reaction conversion (a) and reaction selectivity (b).

surface of the catalyst [22]. Choudhary and coworkers [58] reported that the rate of the Friedel-Crafts acylation using a zeolite-based catalyst was significantly improved in the presence of new Brönsted acid sites formed by the interaction of moisture with the Lewis acid sites of the catalyst. The combination of Lewis acid and Brönsted acid sites could contribute to the catalytic activity of the ZIF-8 in the Friedel-Crafts acylation reaction, but further studies are necessary to elucidate the acid centers present in the catalyst, and the mechanism of the Friedel-Crafts acylation using the ZIF-8 catalyst.

When one uses a solid catalyst, a crucial issue that should be taken into consideration is the ease of separation as well as the deactivation and reusability of the catalyst. The ZIF-8 catalyst was therefore investigated for recoverability and reusability over five successive runs. The reaction was carried out at $120{ }^{\circ} \mathrm{C}$ using the reagent molar ratio of $1: 2$ and 6 mol\% catalyst for $6 \mathrm{~h}$. After each run, the catalyst was separated from the reaction mixture by simple centrifugation, then washed with copious amounts of toluene and DCM to remove any physisorbed reagents. The recovered ZIF-8 was dried under vacuum at $100{ }^{\circ} \mathrm{C}$ overnight, and then reused under identical conditions to those of the first run. It was found that the activity of the ZIF-8 catalyst de-
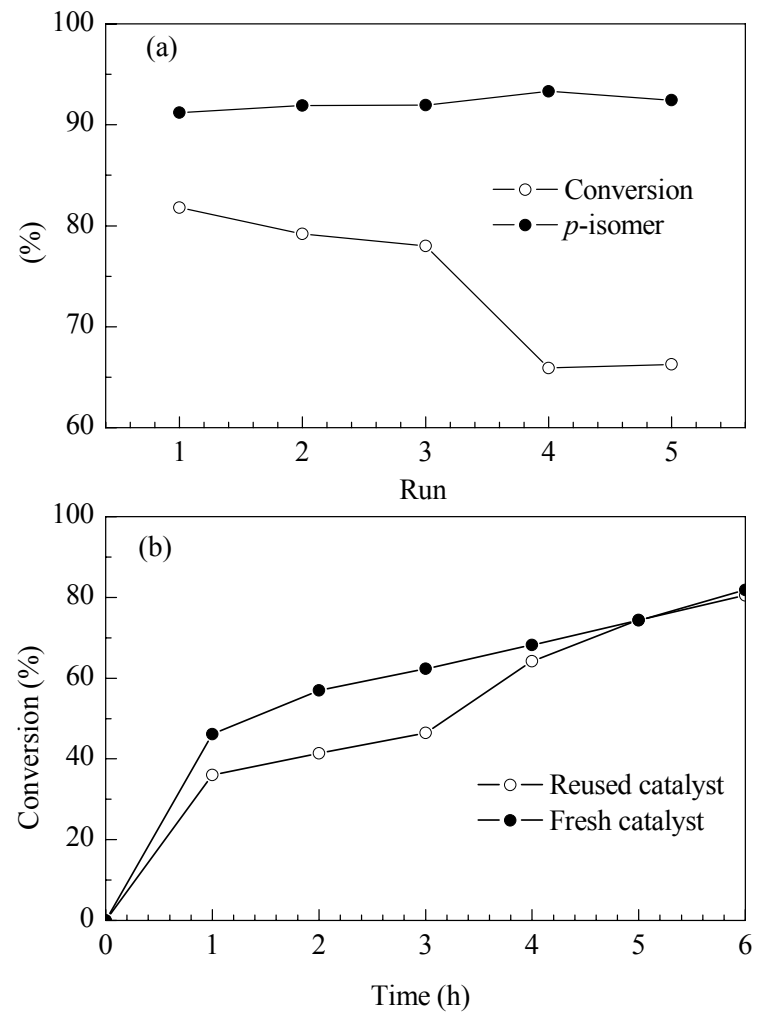

Fig. 13. Catalyst recycling studies.

creased gradually after each run. However, the catalyst could be reused with conversions of $82 \%, 80 \%, 78 \%, 66 \%$, and $66 \%$ after $6 \mathrm{~h}$ for the 1st, 2nd, 3rd, 4th, and 5th run, respectively (Fig. 13(a)). Kinetic studies also indicated that the catalytic activity of the ZIF-8 decreased slightly after each use (Fig. 13(b)). The reaction selectivity remained almost unchanged with $93 \%-95 \%$ of $p$-benzoylanisole being observed in all cases. As compared with the FT-IR spectra of the fresh catalyst, a slight difference was observed with the ZIF-8 after the first run (Fig. 14). XRD result of the reused catalyst revealed that the ZIF- 8 maintained its crystallinity during the course of the reaction. However, a slight

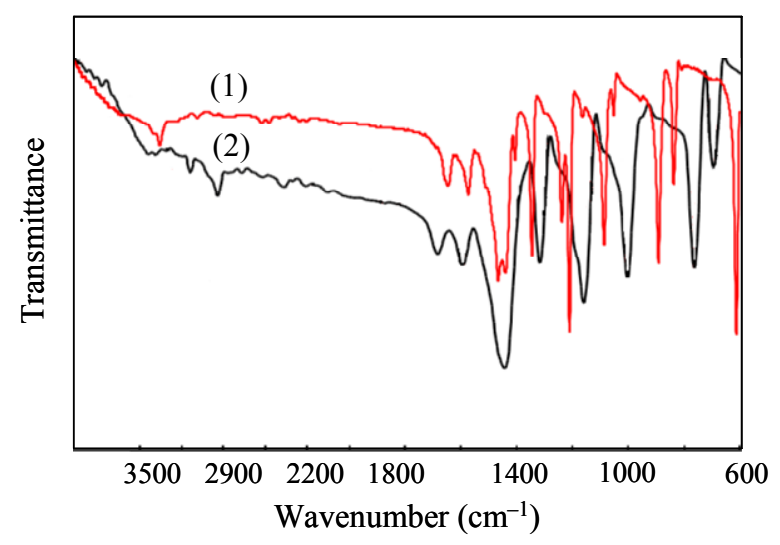

Fig. 14. FT-IR spectra of the reused (1) and fresh (2) ZIF-8. 


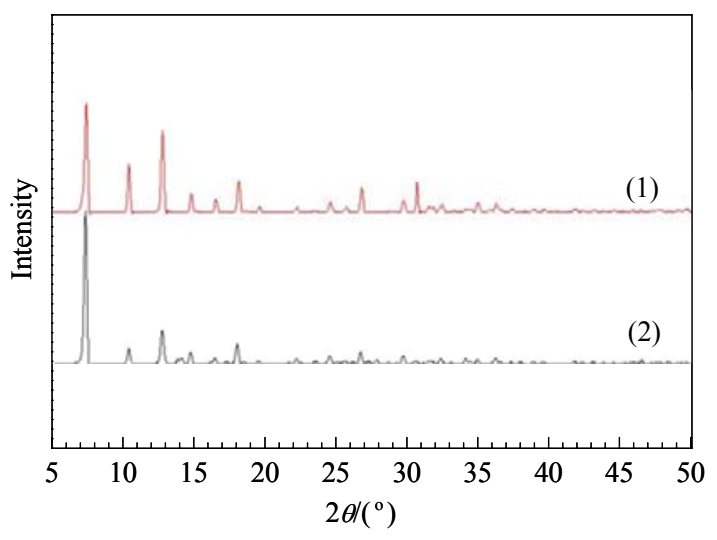

Fig. 15. XRD patterns of the fresh (1) and reused (2) ZIF-8.

difference in the overall structure was observed for the reused ZIF-8 (Fig. 15). Further investigations are needed to clarify the reason of catalyst deactivation in the Friedel-Crafts acylation reaction using the ZIF-8 catalyst.

\section{Conclusions}

Highly crystalline and porous ZIF-8 was synthesized from the reaction of zinc nitrate hexahydrate and 2-methylimidazole by a solvothermal method. The ZIF-8 was characterized by FT-IR, TEM, SEM, XRD, TGA, AAS, DLS and nitrogen adsorption, and used as catalyst for Friedel-Crafts acylation between anisole and benzoyl chloride. The catalyst afforded high conversions with a catalytic amount (4\%-6\%) without the need for an inert atmosphere. The solid catalyst can be easily separated from the reaction mixture by simple centrifugation or filtration, and can be reused without significant degradation in catalytic activity. There was no active acid leaching into the reaction solution.

\section{References}

1 Chae H K, Siberio-Perez D Y, Kim J, Go Y B, Eddaoudi M, Matzger A J, O'Keeffe M, Yaghi O M. Nature, 2004, 427: 523

2 Tranchemontagne D J, Ni Z, O'keeffe M, Yaghi O M. Angew Chem, Int Ed, 2008, 47: 5136

3 Kaye S S, Dailly A, Yaghi O M, Long J R. J Am Chem Soc, 2007, 129: 14176

4 Furukawa H, Ko N, Go Y B, Aratani N, Choi S B, Choi E, Yazaydin A O, Snurr R Q, O'Keeffe M, Kim J, Yaghi O M. Science, 2010, 329: 424

5 Horcajada P, Chalati T, Serre C, Gillet B, Sebrie C, Baati T, Eubank J F, Heurtaux D, Clayette P, Kreuz C, Chang J S, Hwang Y K, Marsaud V, Bories P N, Cynober L, Gil S, Ferey G, Couvreur P, Gref R. Nature Mater, 2010, 9: 172

6 Li H, Eddaoudi M, O'Keeffe M, Yaghi M. Nature, 1999, 402: 276

7 Rowsell J L C, Yaghi O M. Microporous Mesoporous Mater,
2004, 73: 3

8 Li Z-Q, Qiu L-G, Xu T, Wu Y, Wang W, Wu Z-Y, Jiang X. Mater Lett, 2009, 63: 78

9 Phan N T S, Le K K A, Phan T D. Appl Catal A, 2010, 382: 246

10 Ravon U, Savonnet M, Aguado S, Domine M E, Janneau E, Farrusseng D. Microporous Mesoporous Mater, 2010, 129: 319

11 Neogi S, Sharma M K, Bharadwaj P K. J Mol Catal A, 2009, 299: 1

12 Gascon J, Aktay U, Hernandez-Alonso M D, van Klink G P M, Kapteijn F. J Catal, 2009, 261: 75

13 Dewa T, Saiki T, Aoyama Y. J Am Chem Soc, 2001, 123: 502

14 Xamena F X L i, Casanova O, Tailleur R G, H. Garcia A C. J Catal, 2008, 255: 220

15 Liu H, Liu Y, Li Y, Tang Z, Jiang H. J Phys Chem C, 2010, 114: 13362

16 Dhakshinamoorthy A, Alvaro M, Garcia H. J Catal, 2009, 267: 1

17 Kleist W, Maciejewski M, Baiker A. Thermochim Acta, 2010, 499: 71

18 Dhakshinamoorthy A, Alvaro M, Garcia H. Chem Commun, 2010: 6476

19 Phan A, Doonan C J, Uribe-Romo F J, Knobler C B, O'Keeffe M, Yaghi O M. Acc Chem Res, 2010, 43: 58

20 Venna S R, Carreon M A. J Am Chem Soc, 2010, 132: 76

21 Jiang H-L, Liu B, Akita T, Haruta M, Sakurai H, Xu Q. J Am Chem Soc, 2009, 131: 11302

22 Chizallet C, Lazare S, Bazer-Bachi D, Bonnier F, Lecocq V, Soyer E, Quoineaud A-A, Bats N. J Am Chem Soc, 2010, 132: 12365

23 Tran U P N, Le K K A, Phan N T S. ACS Catal, 2011, 1: 120

24 Kapoor M P, Kasama Y, Yanagi M, Yokoyama T, Inagaki S, Shimada T, Nanbu H, Juneja L R. Microporous Mesoporous Mater, 2007, 101: 231

25 Jang D O, Moon K S, Choa D H, Kim J-G. Tetrahedron Lett, 2006, 47: 6063

26 Mantri K, Komura K, Y Kubota, Sugi Y. J Mol Catal A, 2005, 236: 168

27 de Noronha R G, Ferrandes A C, Roao C C. Tetrahedron Lett, 2009, 50: 1407

28 Beltrame P, Zuretti G. Green Chem, 2004, 6: 7

29 Kantam M L, Ranganath K V S, Sateesh M, Kumar K B S, Choudary B M. J Mol Catal A, 2005, 225: 15

30 Álvaro V F D, Brigas A F, Derouane E G, Lourenço J P, Santos B S. J Mol Catal A, 2009, 305: 100

31 Bejblová M, Procházková D, Čejka J. ChemSusChem, 2009, 2: 486

32 Serrano D P, García R A, Otero D. Appl Catal A, 2009, 359: 69

33 Yadav G D, George G. Microporous Mesoporous Mater, 2006, 96: 36

34 Choudhary V R, Jha R. Catal Commun, 2008, 9: 1101

35 Yadav G D, Badure O V. Appl Catal A, 2008, 348: 16

36 Khatri C, Jain D, Rani A. Fuel, 2010, 89: 3853

37 Selvakumar S, Gupta N M, Singh A P. Appl Catal A, 2010, 
372: 130

38 Berrichi F Z E, Pham-Huu C, Cherif L, Louis B, Ledoux M J. Catal Commun, 2011, 12: 790

39 Zane F, Melada S, Signoretto M, Pinna F. Appl Catal A, 2006, 299: 137

40 Procházková D, Bejblová M, Vlk J, Vinu A, Štěpnička $\mathrm{P}$, Čejka J. Chem Eur J, 2010, 16: 7773

41 Ashoka S, Chithaiah P, Thipperudraiah K V, Chandrappa G T. Inorg Chim Acta, 2010, 343: 3442

42 Boroujeni K P. Chin Chem Lett, 2010, 21: 1395

43 Park K S, Ni Z, Côté A P, Choi J Y, Huang R D, Uribe-Romo F J, Chae H K, O'Keeffe M, Yaghi O M. Proc Natl Acad Sci USA, 2006, 103: 10186

44 Banerjee R, Phan A, Wang B, Knobler C, Furukawa H, O'Keeffe M, Yaghi O M. Science, 2008, 319: 939

45 Roswell J, Yaghi O M. J Am Chem Soc, 2006, 128: 1304

46 Chui S S-Y, Lo S M-F, Charmant J P H, Orpen A G, Williams I D. Science, 1999, 283: 1148

47 Lu G, Hupp J T. J Am Chem Soc, 2010, 132: 7832

48 Zhao D, Huo Q, Feng J, Chmelka B F, Stucky G D. J Am Chem Soc, 1998, 120: 6024
49 Hachuła B, Nowak M, Kusz J. J Chem Crystallogr, 2010, 40: 201

50 Cravillon J, Munzer S, Lohmeier S-J, Feldhoff A, Huber K, Wiebcke M. Chem Mater, 2009, 21: 1410

51 Chang N, Gu Z-Y, Yan X-P. J Am Chem Soc, 2010, 132: 13645

52 Repichet S, Roux C L, Roquesb N, Dubac J. Tetrahedron Lett, 2003, 44: 2037

53 Desmurs J R, Labrouillre M, Roux C L, Gaspard H, Laporterie A, Dubac J. Tetrahedron Lett, 1997, 38: 8871

54 Kobayashi S, lwamoto S. Tetrahedron Lett, 1998, 39: 4697

55 Phan N T S, Jones C W. J Mol Catal A, 2006, 253: 123

56 Posternak A G, Garlyauskayte R Y, Yagupolskii L M. Tetrahedron Lett, 2009, 50: 446

57 Firouzabadi H, Iranpoor N, Nowrouzi F. Tetraheadron, 2004, 60: 10843

58 Choudhary V R, Jana S K, Patil N S, Bhargava S K. Microporous Mesoporous Mater, 2003, 57: 21

59 Singh R P, Kamble R M, Chandra K L, Saravanan P, Singh V K. Tetrahedron, 2001, 57: 241

60 Patil P T, Malshe K M, Kumar P, Dongare M K, Kemnitz E. Catal Commun, 2002, 3: 411

61 Selvin R, Hsu H-L, Her T-M. Catal Commun, 2008, 10: 169 